\title{
Advanced glycation end-products: a review
}

\author{
R.Singh, A. Barden, T. Mori, L. Beilin \\ Dept of Medicine, University of Western Australia and West Australian Heart Research Institute, Perth, Australia
}

\begin{abstract}
Advanced glycation end-products are a complex and heterogeneous group of compounds that have been implicated in diabetes related complications. At present it is not known if they are the cause or the consequence of the complications observed. We discuss the chemistry of advanced glycated end-product formation and their patho-biochemistry particularly in relation to the diabetic microvascular complications of retinopathy, neuropathy and nephropathy as well as their role in the accelerated vasculopathy observed in diabetes. The concept of carbonyl stress as a cause for advanced glycated end-product toxicity is mentioned. We discuss alterations in the concentrations of advanced glycated end-products in the body, par-
\end{abstract}

ticularly in relation to changes occuring with age, diabetes and its complications such as nephropathy. Problems relating to current methods of advanced glycated end-product detection and measurement are highlighted including the lack of a universally established method of detection or unit of measurement. Agents used for the treatment of advanced glycated end-product accumulation are reviewed, with an emphasis on the results of the recent phase III trials using aminoguanidine and diabetes related complications. [Diabetologia (2001) 44: 129-146]

Keywords Advanced glycated end-products, diabetes mellitus, microvascular disease, carbonyl stress, aminoguanidine.
Corresponding author: Dr R.Singh MRCP (UK), FRACP, University Dept of Medicine, Royal Perth Hospital, PO Box X2213, Perth 6847, Western Australia

Abbreviations: ESRD, End-stage renal disease; 3-DG, 3-deoxyglucosone; MGO, methylglyoxal; DOLD, deoxyglucosone-lysine dimer; MOLD, methyl glyoxal-lysine dimer; CML, $N^{\varepsilon}$-[carboxymethyl]-lysine; FFI, furoyl-furanyl imidazole; PTB, phenacyl thiozolium bromide; RAGE, receptor for AGE; NF- $\varkappa$ B, nuclear factor- $\varkappa$ B ; VCAM-1, vascular cell adhesion molecule-1; ICAM-1, intracellular adhesion molecule-1; PECAM-1, platelet endothelial cell adhesion molecule-1; ELAM-1, endothelial leucocyte adhesion molecule-1; MSR, macrophage scavenger receptor; $\mathrm{PG}-\mathrm{I}_{2}$, prostaglandin $\mathrm{I}_{2}$; PAI-1, plasminogen activator inhibitor-1; OPB-9195, 2-Isopropylidenehydrazone-4-oxo-thiazolidin-5-ylacetanalide; 2, 3 DAP, 2, 3 di-amino phenazine; VEGF, vascular endothelial growth factor; PI3 kinase, phosphatidyl inositol-3-OH-kinase; MAP, mitogen activated protein.
Diabetes is a common condition with multiple complications. There has been much work done to elaborate on the aetiology, prevention and treatment of diabetes related complications. The DCCT [1] and UKPDS [2] studies have emphasised the role of tight glucose control as being important in reducing diabetic microvascular disease in Type I (insulin-dependent) diabetes mellitus (DCCT) and Type II (non-insulin-dependent) diabetes mellitus (UKPDS). The relation between tight glucose control and macrovascular complications is, however, not clear [3]. Recently the importance of blood pressure control in reducing diabetic microvascular complications has been shown [4]. Apart from these factors, damage induced by hyperglycaemia involves a complex interaction between many influences including genetic predisposition, smoking, BMI, dyslipidaemia and alterations in coagulation factors [3]. The presence of advanced glycation end-products (AGE) is closely related to 
hyperglycaemia and their patho-biochemistry could explain many of the changes observed in diabetes related complications.

The study of AGE represents one of the most promising areas of research today. Although the initial chemistry behind their formation has been known since the early 1900's, it is only in the last 20 years or so that important work has been done to elaborate on this. The chemical processes and pathways that ultimately lead to AGE formation have, however, yet to be fully clarified [5]. As our knowledge of AGE chemistry increases it is becoming apparent that not all AGE have been isolated, whereas those that have been characterised are both complex and heterogenous.

Apart from diabetic microvascular disease, AGE have also been implicated in a wide and seemingly disparate range of pathologies such as connective tissue diseases particularly in rheumatoid arthritis and neurological conditions such as Alzheimer's disease and end-stage renal disease (ESRD) [6-8]. Whether they are the cause of such pathologies or merely a by-product is not known.

In vitro work has mostly shown AGE to be part of complex interactions within oxidative stress and vascular damage, particularly in atherosclerosis [9] and in the accelerated vascular damage that occurs in diabetes, as well as in other conditions such as ESRD $[10,11]$. Histopathological studies have shown AGE accumulation in a variety of tissue types, including coronary atheroma, renal cortex, mesangium and glomerular basement membrane [12], as well as the dermal layer [13], amyloid plaques in Alzheimer's disease [14], cartilage in rheumatoid arthritis [15], cardiac muscle, lung and liver [16].

Apart from their presence in a wide variety of body tissues, AGE have also been identified from exogenously derived sources such as tobacco [17] and certain foods, particularly those that are heated [18]. What contribution these exogenously derived AGE make to AGE patho-biochemistry has not been explained.

Despite their complexity and widespread pathological distribution, the currently known AGE produce the same chemical outcome. That is, the formation of covalent cross-links between proteins, which are thought to be one of the central underlying processes by which they cause damage [19].

Even though many questions concerning AGE chemistry have yet to be defined, a further complication is that currently there is no universally accepted method to detect AGE, no internal standards, nor an internationally recognised standard unit of measurement. Consequently, this makes comparisons of results between different laboratories difficult.

As characterising AGE is proving to be a challenge, therapeutic modalities to deal with their consequences are being investigated. Outcomes of AGE treatment could therefore shed light as to their physiological significance. One such drug that might do this is aminoguanidine, which cleaves AGE-induced chemical cross-links. Animal studies and recently reported phase III trials using this drug have shown some promise in limiting the progression of a number of diabetes related complications such as retinopathy, neuropathy and nephropathy [20-24].

\section{Formation and Structure of AGE}

Reducing sugars such as glucose, react non-enzymatically with amino groups in proteins, lipids and nucleic acids through a series of reactions forming Schiff bases and Amadori products to produce AGE (Fig.1). This process, also known as the Maillard reaction was described in the early 1900's, when it was noted that amino acids heated in the presence of reducing sugars developed a characteristic yellowbrown colour $[5,9]$.

Advanced glycation occurs over a period of weeks, thereby affecting long-lived proteins. Structural components of the connective tissue matrix or basement membrane, such as collagen, are prime targets but can also include myelin, complement $\mathrm{C} 3$, tubulin, plasminogen activator and fibrinogen [20, 25]. In uraemia, however, which is associated with very high concentrations of AGE accumulation, even shorter lived compounds such as lipid constituents and nucleic acids are affected [26].

Glycation is concentration-dependent in the early rather than later stages of the Maillard reaction and so it is enhanced in diabetes $[27,28]$. The formation of AGE is catalysed by transitional metals and is inhibited by reducing compounds such as ascorbate [29]. Glucose has the slowest glycation rate, whereas intracellular sugars, such as glucose-6-phosphate and fructose, form AGE at a faster rate [12]. If oxidation accompanies glycation then the products formed are also known as glycoxidation products. The AGE pentosidine and $N^{\varepsilon}$-[carboxymethyl]-lysine (CML) are such examples (Fig. 1) [12, 30].

Of importance in the Maillard reaction is the formation of reactive intermediate products during Amadori rearrangement. These compounds are known as $\alpha$ - dicarbonyls or oxoaldehydes and include such products as 3-deoxyglucosone (3-DG) and methylglyoxal (MGO) [31-33]. The 3-DG is formed by non-oxidative rearrangement and hydrolysis of Amadori adducts [33] and from fructose-3-phosphate which is a product of the polyol pathway (Fig. 1) [34, 35]. The latter has been implicated as one of the mechanisms that leads to hyperglycaemia induced damage in diabetes [35, 36]. Methylglyoxal is also formed from non-oxidative mechanisms in anaerobic glycolysis [37] and from oxidative decomposition of polyunsaturated fatty acids [38]. In addition, MGO 


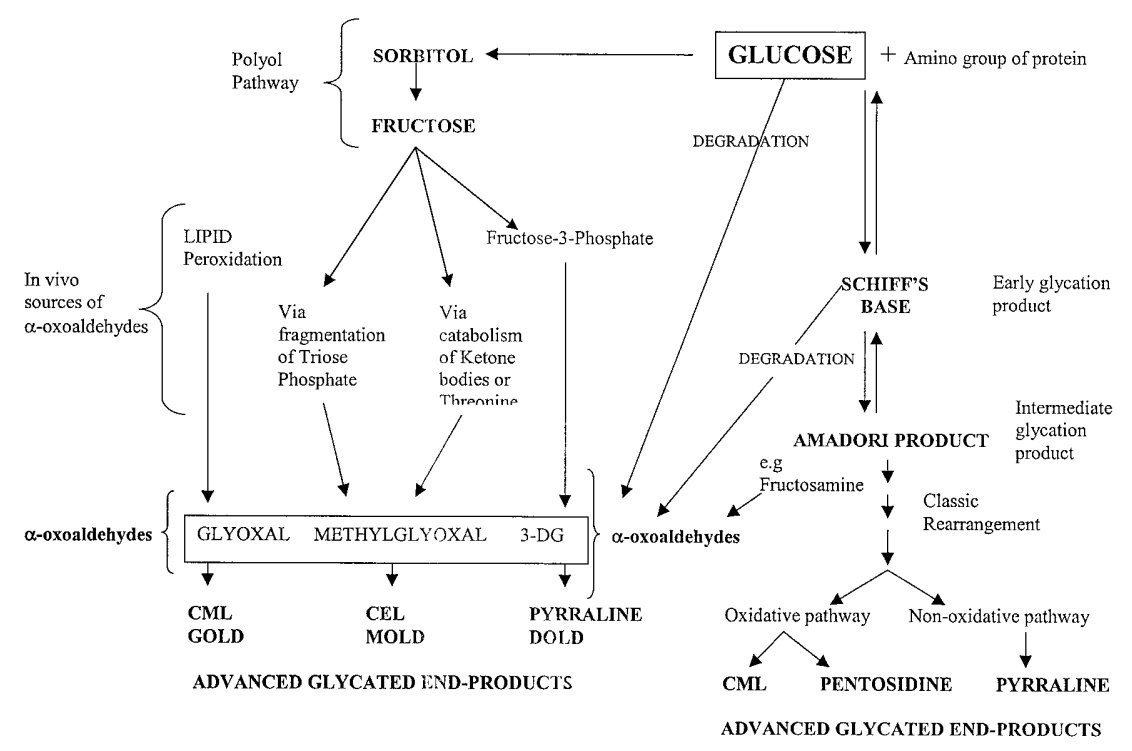

Fig. 1. Glucose and AGE formation pathways incorporating the polyol pathway and AGE formation by the $\alpha$-oxoaldehydes glyoxal, methyl glyoxal and 3-DG. 3-DG, 3-deoxyglucosone; MGO, methylglyoxal; CML, N- $\varepsilon$-(carboxymethyl)lysine; CEL, N- $\varepsilon$-(carboxyethyl)lysine; DOLD, deoxyglucasone-lysine dimer; MOLD, methyl glyoxal-lysine dimer; GOLD, glyoxal-lysine dimer

can be derived from fructose by fragmentation of triose phosphate or the catabolism of ketone bodies and threonine [39]. Although such products have been derived principally by non-oxidative means, they might paradoxically induce oxidative stress and cellular apoptosis [40].

Methylglyoxal, 3-DG and glyoxal have recently been proposed to be formed from all stages of the glycation process (Fig. 1) [39] by degradation of glucose or Schiff's bases in early glycation, or from Amadori products such as fructosamine in the intermediate stages of glycation. Thus $\alpha$-oxoaldahydes could be considered as important focal points of how glucose can go on to form AGE by the classical Maillard reaction, the polyol pathway, as well as from in vivo factors such as the catabolism of ketone bodies and threonine, and lipid peroxidation.

The accumulation of reactive di-carbonyl precursors or of glycoxidation or both and lipoxidation products is termed carbonyl stress [41, 42]. That is, the accumulation of carbonyl precursors whether they go on to form oxidative AGE such as CML and pentosidine or non-oxidative AGE derived from 3-DG [deoxyglucasone-lysine dimer (DOLD)] or MGO [Methyl glyoxal lysine dimer (MOLD)] [43]. This recently described phenomenon of carbonyl stress has been observed in both diabetes and uraemia and has been implicated in the accelerated vascular damage observed in both conditions [9].
The structure of some AGE have been identified including CML, pentosidine and pyralline (Fig.2). Furoyl-furanyl imidazole (FFI), was considered an AGE but has subsequently been shown to be an artefact of sample preparation [32]. The known AGE are immunologically distinct and coexist on different carrier proteins such as albumin, haemoglobin, lens crystalline and LDL cholesterol [29]. In blood $90 \%$ of pentosidine and CML are protein bound to albumin with $10 \%$ being free [44].

Pentosidine and CML are the best characterised as AGE and are referred to as glycoxidation products. Evidence for this comes from in vitro experiments in which anti-oxidants resulted in a reduction in CML formation [45]. Metal catalysed oxidation of polyunsaturated fatty acids in the presence of proteins can also lead to CML formation suggesting that lipid oxidation has a role in AGE formation [46, 47]. Therefore, CML could serve as a general bio-marker of oxidative stress resulting from carbohydrate and lipid oxidation reactions [48].

Glycated haemoglobin. Glycation of haemoglobin forms $\mathrm{HbA}_{1 \mathrm{c}}$ which has been described as an Amadori product [25] but it is not an AGE [49]. It is an indicator of glycaemia from the preceding 6 to 12 weeks, whereas advanced glycation reflects a process that can occur over a longer period.

\section{Exogenous AGE}

Tobacco and Food derived AGE. The formation of AGE is usually endogenous but can be derived from exogenous sources such as tobacco smoke or food $[17,18,50]$. Although it is well recognised that cigarette smoking can lead to vascular disease, what role exogenous AGE have in contributing to this process, especially in diabetes, is not known. Nevertheless to- 


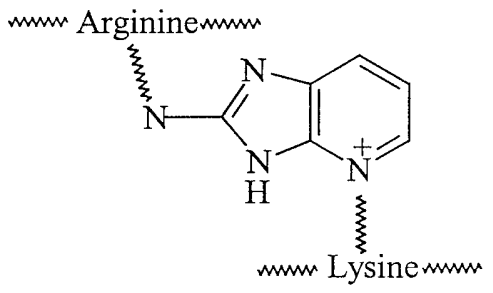

PENTOSIDINE
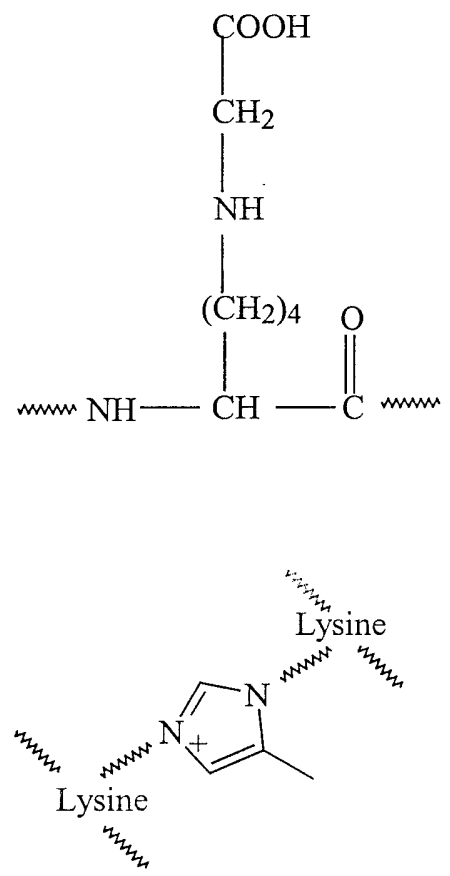

MOLD

Fig. 2. Structure of the AGE CML, pentosidine and MOLD

bacco derived AGE have been observed in lens crystalline and coronary artery vascular walls [17]. Although the mechanism of AGE formation from cigarette smoke and the types of AGE formed are not known, animal studies examining tendon collagen suggest they contain carbonyl groups [50].

Heat treatment of food results in non-enzymatic browning, otherwise known as the Maillard reaction [18]. Because of the heterogenous nature of chemical moieties and the lack of sensitive methodologies, quantifying the contribution of exogenous or foodderived AGE has been difficult [51]. Oral bio-availability is, however, thought to be low ( $\sim 10 \%)$, secondary to poor absorption from the gastrointestinal tract, as AGE cross-link formation is resistant to enzymatic or chemical hydrolysis [51]. It has been proposed that the accumulation of food derived AGE in uraemia can act as glycotoxins resulting in cytokine generation and histological changes showing glomerular damage [52]. Whether the same is true for diabetes is not known.
Unfortunately, dietary based studies can be confounded by the type and amount of food consumed and give no insight into the specific AGE responsible for the damage observed. More work is required to differentiate between endogenous and exogenously derived AGE and then relate this to histological damage observed.

\section{AGE and Cross-link formation}

Despite the heterogeneity of AGE structures, a common consequence of their formation is covalent cross-link formation. Proteins affected by this process are usually stable and long lived, such as collagen. The chemistry behind cross-link formation is complex and not fully understood but is thought to involve lysine residues [53]. This is supported by in vitro work using the agent phenacyl thiozolium bromide which is said to cleave chemical cross-links between two lysine residues [21]. Physiological cross-linking, which also tends to involve collagen, is better understood and requires the enzyme lysyl oxidase. There is, however, no evidence that this type of cross-linking is involved in the accelerated cross-linking seen in diabetes mellitus with AGE [53]. The pathological cross-link formation induced by AGE leads to increased stiffness of the protein matrix, hence impeding function as well as increasing resistance to removal by proteolytic means, which in turn affects the process of tissue remodelling. These changes occur with advancing age and are accelerated in diabetes [28, $54,55]$. Histological studies support these findings, using human aortas obtained from post-mortem examinations and showed a correlation between AGE tissue accumulation and aortic stiffness [56]. In addition, immunostaining methods using specific antibodies have shown increased accumulation of the AGE pyrraline, crossline and pentosidine (considered to be a good bio-marker of AGE cross-linking), in the kidneys of diabetic subjects [27, 28, 57].

Physiological consequences of cross-link formation include sclerosis of renal glomeruli, thickening of the capillary basement membrane and atherosclerosis development [53]. Atherosclerosis is thought to involve not only cross-linking but also trapping of lipoproteins by AGE formed on the matrix component of vessel walls [12]. This impairs cholesterol efflux from the vessel wall leading to lipoprotein accumulation and macrovascular disease [29].

\section{AGE and their interaction with AGE receptors}

Several AGE receptors have been identified and include macrophage scavenger receptor Types I and II, receptor for AGE (RAGE), oligosaccaharyl transferase-48 (AGE-R1), 80K-H phosphoprotein (AGE- 


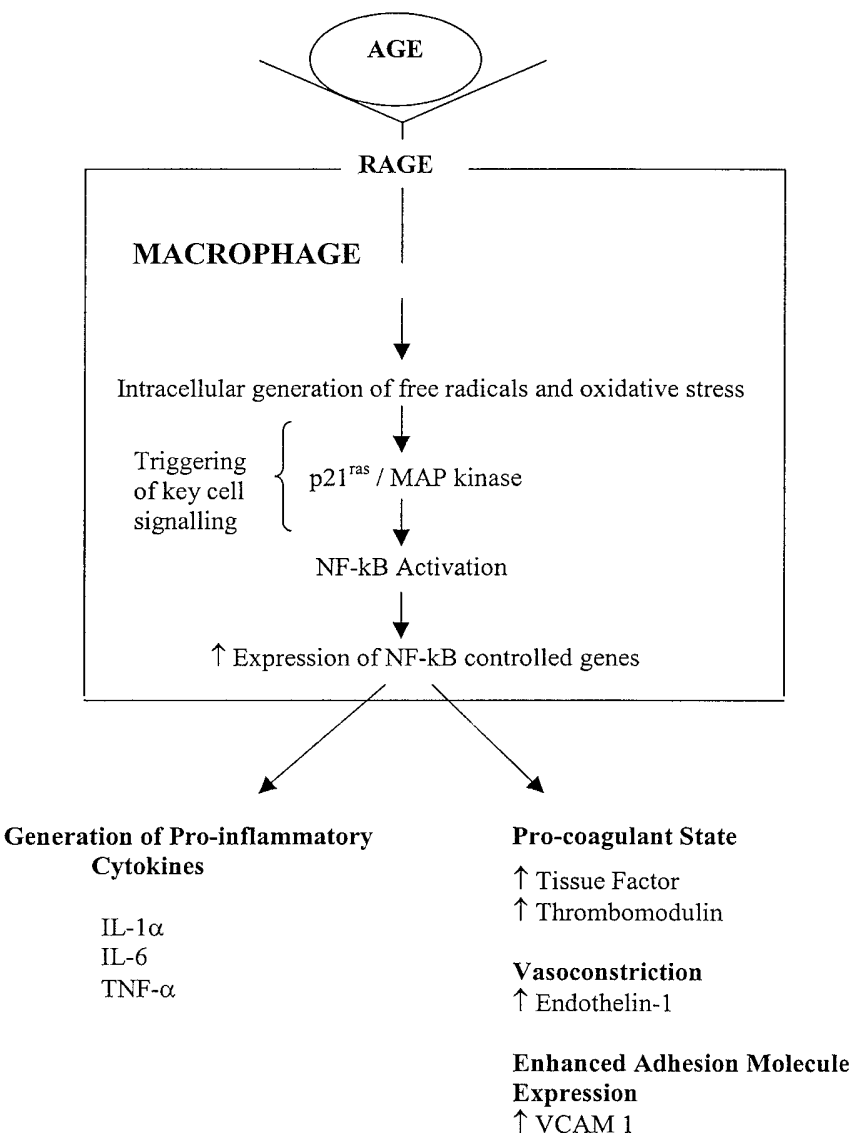

Fig. 3. AGE-RAGE interaction and NF- $\varkappa \mathrm{B}$ activation leading to oxidant stress, vasoconstriction and a procoagulant state

R2) and galectin-3 (AGE-R3) [58]. They are expressed on a wide range of cells including smooth muscle cells, monocytes, macrophages, endothelial cells, podocytes, astrocytes and microglia [59]. The expression of some of these receptors is increased in diabetes, for example, galectin-3 expression is increased in diabetic animal models [60]. Similarly RAGE expression is increased in the blood vessels and kidneys of diabetic patients as opposed to control subjects [61, 62]. The best characterised AGE receptor is RAGE, which is a multiligand member of the immunoglobulin superfamily [63]. The RAGE receptor is thought to act as a scavenger and mediate intracellular signalling. Using immunostaining methods it has been located on endothelial cells, specifically in areas of atherosclerosis $[61,63]$. In vitro studies have shown that AGE-RAGE binding on macrophages and microglia leads to oxidant stress and activation of the transcription factor NF- $x \mathrm{~B}$ (Fig. 3) [62, 64, 65]. This process involves the activation of the $\mathrm{p} 21^{\text {ras/ }}$ MAP kinase signalling cascade, which then activates $\mathrm{NF}-\varkappa \mathrm{B}$. Evidence for this comes from inhibition of p21 ${ }^{\text {ras }}$ which blocks NF- $\varkappa$ B activation [62]. The NF$\varkappa \mathrm{B}$ is a free radical sensitive transcription factor that modulates gene transcription for endothelin-1,
VCAM-1, tissue factor and thrombomodulin [12]. It has also been linked to states of anti-oxidant depletion induced by AGE, with a reduction in glutathione, vitamin $\mathrm{C}$ and nitric oxide [66]. Further evidence of an interaction between AGE and the NF- $x \mathrm{~B}$ pathway can be shown from in vitro studies using hyaluronic acid, which is a glycosaminoglycan polymer that inhibits AGE-induced activation of NF- $x \mathrm{~B}$ and NF- $x \mathrm{~B}$ regulated release of IL- $1 \alpha$, IL- 6 and TNF $\alpha$ [67].

Although these studies require confirmation, it appears that AGE-RAGE interaction leading to oxidant stress could be of importance at sites of inflammation. Evidence for this comes from studies looking at phagocytes at sites of inflammation showing that they generate CML through myeloperoxidase - a haem protein released by activated phagocytes [68]. This pathway is independent of hyperglycaemia and might explain the presence of AGE in atherosclerotic lesions found in non-diabetic subjects as well as in patients with inflammatory conditions such as rheumatoid arthritis.

Animal studies using soluble RAGE, which blocks the RAGE receptor, has shown a suppression of vascular lesion formation as well as a reduction in vascular permeability and hence dysfunction [69]. This process is independent of lipid and glycaemic changes suggesting that other mechanisms, such as AGE accumulation, are important in contributing to vascular disease.

A "two hit" model has been proposed to explain vascular dysfunction involving AGE [69]. It involves an initial AGE-RAGE interaction resulting in cellular activation and inflammation, followed by lipoprotein accumulation in atherosclerosis, leading to chronic inflammation and further accelerated atherosclerosis.

Despite in vitro work little is known about the in vivo ligands of RAGE, or the other putative AGE receptors [33]. Currently there are three known major ligands for RAGE including AGE, amphoterin (a member of the high mobility group proteins) and amyloid $\beta$-peptide, which is thought to be important in the pathogenesis of Alzheimer's disease [70]. A recent study examining amphoterin-RAGE interaction found that amphoterin, a neurite outgrowth-promoting protein, is thought to influence the migration of immature and malignant cells [71]. This has been recently shown using animal models where blockage of amphoterin-RAGE signalling resulted in suppression of tumour growth [72]. Currently AGE-RAGE interaction is thought to occur by a separate and distinct signalling pathway to that of amphoterin-RAGE interaction [62]. 


\section{Post AGE-receptor effects at the tissue level}

Most research on AGE has centred on diabetes mellitus and its complications. It is well recognised that diabetes is associated with premature atherosclerosis [58] and that endothelial dysfunction and oxidative stress play an important part in this, as manifested by increased concentrations of markers of endothelial dysfunction such as intracellular adhesion molecule-1 (ICAM-1), platelet endothelial cell adhesion molecule-1 (PECAM-1) and endothelial leucocyte adhesion molecule-1 (ELAM-1) [73]. Hyperglycaemia also seems to have a causal role in vascular dysfunction but its mechanism is not clear. A number of hypotheses have been proposed including alteration of redox potentials, the sorbitol hypothesis and nonenzymatic glycation [29, 74].

Non-enzymatic glycation is accelerated in hyperglycaemic conditions but also occurs in the non-diabetic state. The process of advanced glycation itself is not harmful, only the products of it [75]. In addition the rate of accumulation of these end-products is related to the severity of complications observed. For diabetic patients this relates to neuropathy, nephropathy, retinopathy and lens disorders [20, 28, 32, 76]. Although there is increasing evidence for AGE involvement in these complications there have yet to be definitive human studies to confirm these observations $[32,58]$. For instance, healthy older non-diabetic subjects have greater tissue AGE accumulation than younger insulin-dependent diabetic subjects who have microvascular complications [32]. This could suggest that it is perhaps the rate of accumulation rather than the absolute concentration of AGE that is important. Despite these reservations there is in vitro and diabetic animal model evidence that AGE accumulation has a number of important consequences at the tissue level (Table 1). These include lipid peroxidation and endothelial dysfunction [12, $20]$ and inappropriate cellular activity with cytokine release [20, 77]. Alterations in cell spreading [55] and other structural changes such as cross-link formation have also been described [20, 27, 32, 77, 78].

\section{AGE metabolism}

It has been proposed that the principal mechanism for the degradation of AGE modified tissues and cells is specific AGE receptors on tissue macrophages [79]. After degradation small soluble AGE peptides are released and subsequently cleared by the kidney. It follows therefore, that effective elimination is dependent on a normal creatinine clearance. Any deterioration in renal function results in AGE accumulation which can lead to endothelial perturbation and hence vascular disease [12]. More recently it has been suggested that scavenger receptors expressed by liver sinusoidal cells such as kupffer and endothelial cells are important mediators in the endocytic uptake of AGE protein from the plasma [80]. Defects in this system or the over production of AGE or both could therefore contribute to AGE accumulation independently of renal function [78].

In vitro studies have proposed that insulin also contributes to AGE elimination from the plasma via the IRS and phosphatidyl-inositol-3-OH kinase (PI3 kinase) pathway [78]. This pathway is thought to be vasculo-protective, leading to a rise in nitric oxide as well as facilitating insulin-mediated glucose transport in adipocytes and skeletal muscle [81]. Liver endothelial cells expressing macrophage scavenger receptors (MSR) showed an insulin-mediated increase in endocytic uptake of labelled AGE. This effect was suppressed by wortmannin, a PI3 kinase inhibitor. Just how insulin receptor signalling couples PI3 kinase to AGE uptake is not known but it is thought to result in an acceleration of MSR mediated endocytic internalisation, vesicle transport, lysosomal degradation and subsequent exocytosis of AGE proteins [78]. Although these observations need to be confirmed in vivo, they contribute to our understanding of insulin function, AGE physiology and could represent a way to control AGE concentrations in diabetic subjects.

\section{AGE concentrations in diabetes, chronological age and renal failure}

Diabetic animal models have shown that AGE concentrations increase within a few weeks after the animal is rendered diabetic and that this increase is systemic, occurring in the kidneys, skin and vascular tissue [33]. A study using rats rendered diabetic after streptozotocin (STZ) injection found that the AGE content (as measured by ELISA), increased in lens tissue, renal cortex and aorta after only 5 weeks. Compared with control rats the AGE-renal content in the diabetic rats was 16-fold greater [82]. Studies using animal models have examined the time required to produce pathological changes; for example, exogenous AGE were given to animals in concentrations sufficient to achieve plasma concentrations equivalent to diabetic animals. After 5 months the renal AGE content was $50 \%$ greater compared with the control animals. Histology of the kidney showed a $50 \%$ expansion of the glomerular volume, basement membrane widened and increased mesangial matrix, indicating statistically significant glomerular sclerosis compared with controls [83].

Under normal conditions advanced glycated haemoglobin (Hb-AGE) accounts for $0.42 \%$ of circulating haemoglobin but this increases to $0.75 \%$ in diabetic subjects [25]. In a phase I clinical trial, $1200 \mathrm{mg}$ a day of aminoguanidine reduced $\mathrm{Hb}-\mathrm{AGE}$ by $28 \%$ 
after 28 days in subjects with diabetes (Type I and Type II), for an average of 20 years.

Using HPLC methods, the concentrations of AGE such as CML and pentosidine rise with age and are approximately doubled in diabetes, correlating with the severity of diabetic microvascular disease [27]. Other studies [6] using ELISA methods to measure serum AGE found increased concentrations in children with Type I diabetes before reaching puberty $(14.5 \pm 2.8$ $\mathrm{U} / \mathrm{ml}$ ) compared with age-matched control children $(11.4 \pm 2.9 \mathrm{U} / \mathrm{ml}), p<0.01$. Adolescents with microvascular disease had higher concentrations $(17.9 \pm 2.4 \mathrm{U} / \mathrm{ml})$, compared with those with uncomplicated diabetes $(15.7 \pm 2.3 \mathrm{U} / \mathrm{ml})$ and control adolescents of the same age $(12.2 \pm 1.9 \mathrm{U} / \mathrm{ml})$. Adolescents with proliferative retinopathy had the highest concentrations ( $>20 \mathrm{U} / \mathrm{ml}$ ) of AGE. This study is important because it shows that AGE exist in very young children ( $<6$ years) and that even at this early age diabetic children have much higher concentrations of AGE. In contrast, a study using a fluorimetric immunoassay to measure serum AGE in children with Type I diabetes compared with control children matched for age, found that the Type I diabetic children had significantly higher concentrations than the control children $(14.4 \pm 3.5 \mathrm{U} / \mathrm{ml}$ vs $11.7 \pm 3$, respectively, $p<0.002)$ [84]. No correlation was found between serum AGE and age or duration of diabetes. In addition there were also no sex differences. The lack of an association between AGE and chronological age could be due to a less sensitive assay than those using HPLC or ELISA techniques, which have shown that AGE such as CML for example, rise linearly with age. This is true whether they are measured in serum, skin collagen or lens tissue [11, 27, 85-87].

The AGE concentrations have been compared in diabetic subjects with or without ESRD. Some of the earlier studies using ELISA methods found that diabetic subjects with ESRD had up to a 100-fold increase in serum AGE, compared with those with normal renal function $[79,88]$. Other studies have supported these results by showing increases in serum pentosidine in diabetic subjects of two and a half times and in ESRD up to 23-fold [9]. In addition, pentosidine concentrations have been found to increase with age among subjects with normal renal function [89].

Using radioreceptor methodology, arterial wall AGE have been measured in autopsy samples from subjects with or without diabetes and renal disease [25]. The authors reported the highest concentrations of AGE in diabetic subjects with ESRD $(21.3 \mathrm{U} / \mathrm{mg}$ protein), followed by diabetic subjects without renal disease (14.5 U/mg protein). Both groups were statistically significantly higher than the control group (3.6 AGE U/mg protein) [90].

Apart from CML and pentosidine, pyrraline and 3-DG have been measured in normal and pathologi- cal states. Using HPLC and GC-MS methods pyrraline was detected in human skin and plasma in picomolar concentrations [91]. Similarly, it has been estimated that under normal conditions several milligrams of 3-DG are produced a day, and it is readily detoxified to 3-deoxy fructose and excreted in the urine [92]. The concentrations of 3-DG as measured by HPLC, has been shown to be $314 \mathrm{ng} / \mathrm{ml}$ in control subjects, $778 \mathrm{ng} / \mathrm{ml}$ in uncomplicated diabetes, and $1235 \mathrm{ng} / \mathrm{ml}$ in diabetics with renal disease (defined as a urinary albumin excretion rate of $>200 \mathrm{mg}$ a day) [25].

Tissue AGE concentrations using immunohistochemical methods tend to be arbitrarily quantified, using - as representing zero staining and +++ to signify the most intense staining. Using these methods AGE have been identified in a variety of tissues and cells such as fatty streaks, macrophages and smooth muscle cells. Subjects with vascular disease and diabetes often show an intense staining [93].

\section{Measurement of AGE}

Although there is experimental evidence for AGE accumulation with age and under certain pathological states such as diabetes, it is difficult to compare results between laboratories. Moreover, there are now a number of AGE which are structurally heterogeneous making it difficult to ensure that the AGE detected is relevant to the complications observed in vitro or in vivo. To date AGE measurement is confined to investigative laboratories. Currently there is no commonly accepted or widely used method to detect AGE, nor any commercially available kits. Although there is no universally established unit of measurement, it has recently been proposed to adopt a universal unit of measurement for different laboratories to compare results [94]. The lack of internal standards leaves assays open to error which require a high degree of accuracy and reproducability for each sample run. Currently the most common methods used for detection are HPLC [16, 88], ELISA $[79,95]$ and immunohistochemistry [96]. Recently, a monoclonal antibody which recognises CML, called 6D12, has become commercially available [97, 98].

\section{Consequences of AGE formation in diabetes}

Hyperglycaemia has been implicated in the accelerated vascular damage associated with diabetes, which eventually manifests microvascular complications such as retinopathy, neuropathy, nephropathy and macrovascular disease [55, 83]. Although the mechanisms leading to such complications are not fully understood, three pathways have been proposed: activation of protein kinase $\mathrm{C}$ isoforms, the aldose reduc- 
Table 1. AGE effects at the tissue and cellular level

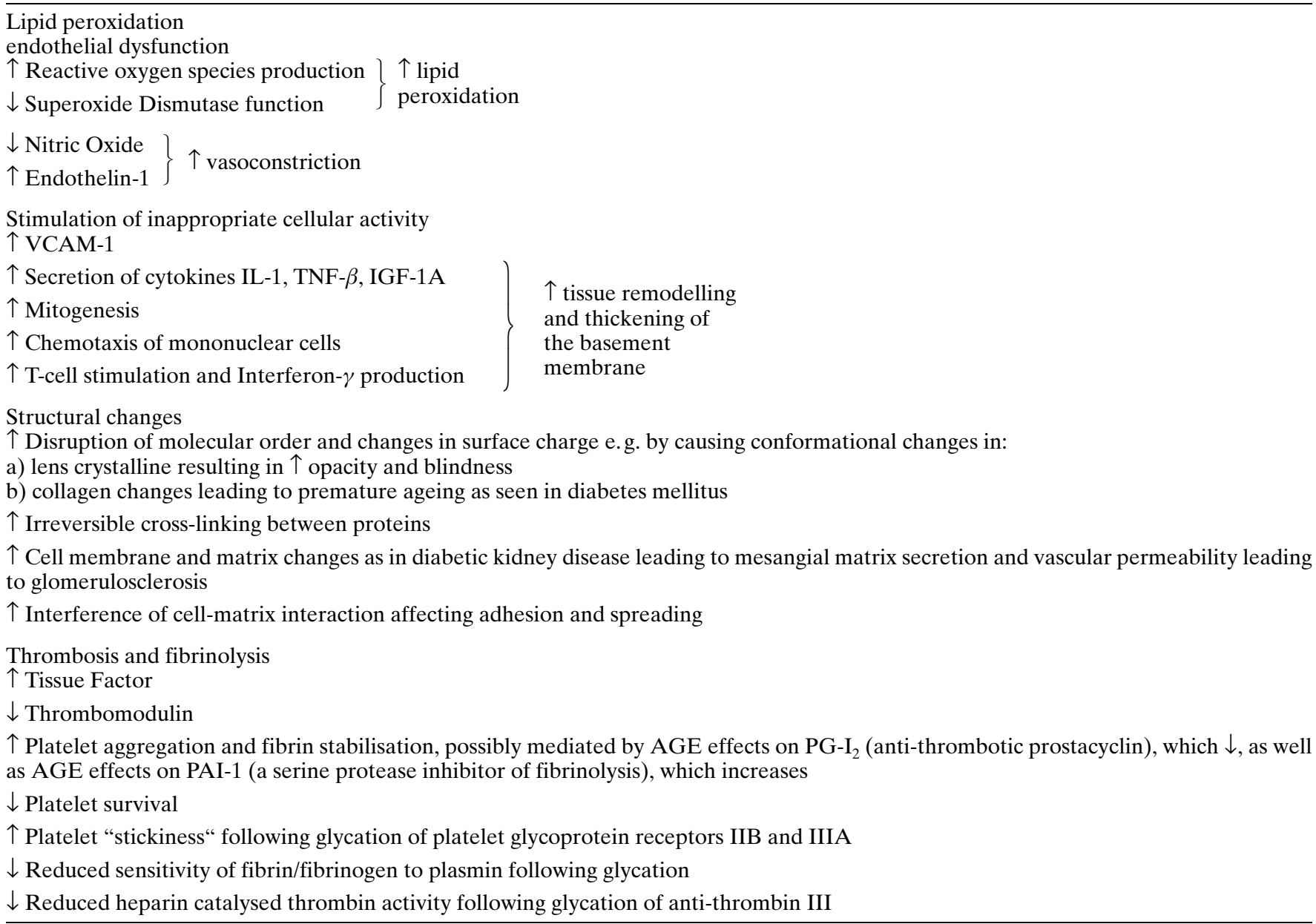

tase pathway and AGE formation [25, 36, 83]. Evidence for their role comes from the use of a protein kinase inhibitor such as LY333531 [99], the aldose reductase inhibitor ponalrestat [100] and use of the soluble extracellular domain of RAGE [101]. All these reduced diabetic complications, albeit in diabetic animal models.

Hyperglycaemia increases production of reactive oxygen species and leads to a state of oxidative stress [102]. Oxidants such as the superoxide anion, hydrogen peroxide and lipid peroxides cause damage by oxidation, fragmentation and cross-linking [25]. Formation of AGE also induces free-radical production as well as depleting nitric oxide concentrations [28], leading to oxidative stress $[102,103]$. As nitric oxide is vasodilatory and has antiproliferative effects on vascular smooth muscle [25], AGE accumulation could therefore result in vascular thickening with loss of elasticity, hypertension and endothelial dysfunction (Table 1). Further evidence for AGE-associated vascular damage comes from cross-linking of sub-endothelial structural proteins such as collagen and laminin. This is thought to affect tissue remodelling resulting in activation of smooth muscle prolifer- ation as well as increasing vascular permeability $[25$, 104] (Table 1). These changes are important in the pathophysiological features associated with diabetes [102].

Other important features of AGE-induced vasculopathy include effects on coagulation and fibrinolysis (Table 1); specifically, reduced platelet survival and increased aggregation [105, 106], alterations in coagulation factors such as anti-thrombin-III, tissue factor and thrombomodulin [12], and effects on fibrin stabilisation [107]. The end result is the promotion of a procoagulant state. A similar state might also occur in diabetes which is associated with alterations in von Willebrand factor and platelet function, as well as attenuation of fibrinolysis with hyperfibrinogenaemia and alterations in coagulation factors such as factor VII [3].

Diabetic retinopathy. Diabetic retinopathy is a common condition affecting $90 \%$ of diabetic subjects with background retinopathy and 8 to $26 \%$ with proliferative retinopathy after 25 years of diabetes [25]. It is characterised by abnormal vessel development leading to haemorrhages, ischaemia and infarctions. 
Specific morphological and functional changes include basement membrane thickening, loss of pericytes and increased permeability [29]. Accumulation of AGE might contribute to this state of vaculopathy by increasing retinal endothelial cell permeability resulting in vascular leakage [108]. Vessel wall thickening and coagulation, leading to occlusion and ischaemia [109] as well as induction of growth factors such as VEGF, resulting in angiogenesis and neovascularisation have also been described [110]. In animal studies intravitreal injection of VEGF has resulted in similar changes to those seen in non-proliferative diabetic retinopathy, mostly manifesting with hyperpermeability of the retinal vessels, leading to oedema, retinal haemorrhages, microaneurysm formation and vessel occlusion [111]. A study comparing post-mortem human retinas between diabetic subjects with background and proliferative retinopathy and nondiabetic subjects, found that CML and VEGF immunoreactivities were distributed around blood vessels in diabetic retinas [111]. None of the control subjects showed CML or VEGF immunoreactivity. Whereas VEGF expression was greater in subjects with proliferative retinopathy, CML accumulation was, however, no different in background or proliferative retinopathy. These data suggest that CML could have a role in VEGF expression in retinopathy but other mechanisms could also be important. For instance VEGF expression is increased in ischaemia [111] and it is recognised that AGE and diabetes have detrimental effects on coagulation factors resulting in ischaemia and occlusion [3]. Thus the effects of AGE could be indirect and accumulation might not have to mirror VEGF expression.

Immunohistochemistry has been used to examine the spatial and temporal distribution of AGE in diabetic and non-diabetic rat retinas [112]. The two AGE examined were CML (a glyoxidation product) and a recently characterised imidazolone type AGE, AG-1 (a non-oxidative AGE). The CML immunoreactivity was greater in diabetic rats than in control rats and was mostly present in neurological elements (ganglion cell, plexiform layer) of the retina. The AG-1 was not found in control rats but localised exclusively to the vasculature of diabetic retinas. In rats with advanced retinopathy, however, both AGE were distributed throughout the retina. We show that CML is present in normal retinas and increased in diabetes. The AG-1 localisation to the vasculature could be explained by the fact that early diabetic retinal damage occurs initially in the microvasculature. Further studies are required to clarify the physiological significance of these findings.

In vitro studies have shown that AGE modification of retinal basement membrane results in reduced retinal pericyte proliferation but increased retinal endothelial cell proliferation. These effects are observed in diabetics and along with AGE effects on ni- tric oxide depletion, reactive oxygen substance production and changes in vessel elasticity, could explain AGE effects on microvascular structure and function [113].

Further evidence for the role of AGE in diabetic retinal vasculopathy comes from diabetic animal model studies using aminoguanidine [29]. These have shown a reduction in microaneurysm formation, endothelial proliferation and pericyte loss. Other studies using diabetic hypertensive rat models have also shown that aminoguanidine inhibited the development of accelerated diabetic retinopathy [113].

Indirect evidence for AGE involvement in diabetic retinopathy comes from studies examining CML and pentosidine accumulation in skin collagen. These showed that AGE accumulation was associated with the severity of retinopathy and the development of early nephropathy [28], independent of age, sex and duration of diabetes.

Cataract formation. Not only are diabetic subjects more likely to develop cataracts but they also occur at an earlier age. Although the underlying mechanisms leading to cataract formation in diabetic subjects has yet to be explained, glycation of lens crystallin and the $\mathrm{Na}^{+} / \mathrm{K}^{+}$-ATPase pump is thought to be important [114]. A recent report suggests that changes in lens crystallin due to glycation and subsequent oxidation plays a major part [115]. In addition, in vitro work has shown that glycation lowers $\mathrm{Na}^{+} / \mathrm{K}^{+}$-ATPase activity leading to alterations in ion and water concentrations, which could in turn lead to osmotic stress and cataract formation [114].

Further evidence for AGE involvement in cataract formation comes from the use of pyruvate, which in animal studies protects the lens from oxidation and the formation of high molecular weight crystallin aggregates by inhibiting AGE formation [114].

Diabetic neuropathy. Diabetic neuropathy is both common and complex in its aetiology and manifestations. All the major nervous systems in the body can be affected including the central, autonomic and peripheral nervous systems. As with retinopathy, diabetic neuropathy manifests according to the concentrations of diabetic control and duration [25]. A number of complex interactions are involved in producing diabetic neuropathy including metabolic abnormalities (polyol pathway, oxidative stress and advanced glycation), functional abnormalities (reduced nerve conduction volume and blood flow), and structural abnormalities (axonal degeneration, fibre demyelination and neuronal apoptosis) [35].

The AGE have been implicated in nerve damage with much work done on the aetiology of Alzheimer's disease and the glycation of amyloid- $\beta$ protein, which is a precursor of the senile plaque seen in this condition [116]. As with diabetic retinopathy there is evi- 
dence of vascular dysfunction and that includes accumulation of AGE in the vasa nervorum leading to wall thickening, ischaemia, occlusion [117] and myelin damage with segmental demyelination [35]. In vitro studies show that glycation of axonal cytoskeletal proteins such as tubulin, actin and neurofilament results in slowed axonal transport, atrophy and degeneration $[35,118]$. In addition, glycation of laminin, an important constituent of Schwann cell basal laminae, impairs its ability to promote nerve fibre regeneration [118, 119]. Advanced glycation has also been reported to affect growth factors such as fibrin and nerve growth factors, causing a loss of function [12, 120]. What effect these largely in vitro changes have on physiological manifestations has yet to be determined. Studies examining AGE effects on peripheral nerves from diabetic rats have, however, shown reductions in sensory motor conduction velocities and nerve action potentials as well as reductions in peripheral nerve blood flow [113]. All these changes have been prevented by pre-treatment with aminoguanidine [113].

Immunoperoxidase staining methods for CML have been used to compare peripheral nerves from both human diabetic and control subjects [121]. This detected CML in the perineurium, endothelial cells, pericytes of endoneurial microvessels as well as in myelinated and unmyelinated fibres of diabetic subjects compared with control subjects. There was also a correlation between the intensity of CML accumulation and myelinated fibre loss suggesting a possible role for advanced glycation in diabetic neuropathy. Despite these observations no direct link could be made between the observed pathological changes in the nerve and localization of AGE accumulation. The authors suggested that the AGE-perineurial interaction could alter the endoneurial microenvironment and microcirculation by inducing oxidative stress and so disrupting the perifasicular diffusion barrier which perineural cells are said to maintain and which is important for normal function.

Although not specifically examining diabetic subjects, a recent study on the cause of amyotrophic lateral sclerosis, a form of motor neurone disease, has suggested that accumulation of the dicarbonyls MGO and 3-DG can lead to neurotoxicity as a result of reactive oxygen species generation [122]. Such a situation could also occur in diabetic nerve damage secondary to AGE accumulation, which itself is associated with oxidative stress and reactive oxygen species production. In vitro studies using cultured spinal motor neurones have shown a protective effect using aminoguanidine, presumably by utilising its anti-oxidant properties which results in the augmentation of glutathione, an important intracellular anti-oxidant. This effect partly explains why aminoguanidine can slow the progression of diabetes-related neuropathy in animal models [76].
$A G E$ and nephropathy. Expansion of the extracellular matrix is one of the dominant histological features of diabetic nephropathy and can lead to basement membrane thickening, vascular leakage and glomerulosclerosis [29, 123]. Animal studies have shown that glomerular hypertrophy is associated with an over expression of type IV collagen, laminin B1, TGF- $\beta$ and platelet derived growth factor, all of which can be ameliorated by aminoguanidine treatment [29, 123]. These effects can be achieved independently of glucose control [124].

Considered to be an important mediator in diabetic nephropathy, TGF- $\beta$ is known as a prosclerotic cytokine, which stimulates the synthesis of collagen matrix components such as fibronectin, laminin and proteoglycans [123]. Both hyperglycaemia and AGE increase TGF- $\beta$ concentrations [125]. Studies using diabetic rats and an AGE inhibitor OPB 9195, showed a reduction in the progression of diabetic nephropathy by blocking type IV collagen formation as well as the overproduction of TGF- $\beta$ and VEGF. The VEGF is produced by podocytes and mesangial cells and is said to also have effects on glomerular proliferation and possibly increased glomerular capillary permeability [126].

In vitro studies using rat mesangial cells have recently shown that exposure to AGE-rich proteins resulted in mesangial oxidative stress and activation of protein kinase C- $\beta$ (II) [103]. These results show that activation of protein kinase $\mathrm{C}$ isoforms have been implicated in the pathogenesis of diabetic complications in diabetic animal models and that blocking it has resulted in reductions in albuminuria [103].

A number of AGE such as CML, pyralline and pentosidine have been identified in the renal tissue of diabetic patients with or without ESRD [11], with AGE accumulation increasing with severity of diabetic nephropathy [11]. Immunohistochemistry using diabetic rat models has shown AGE accumulation in the glomerular extracellular matrix, with concentrations rising with age and more rapidly with diabetes $[127,128]$.

Further evidence for AGE accumulation and glomerular injury comes from recently reported phase III trials using pimagedine (the generic form of aminoguanidine), which suggest that therapy directed at AGE could be important in slowing diabetic nephropathy in optimally treated Type I diabetic subjects [22]. In a double blind, randomised, placebocontrolled trial using pimagedine given as $150 \mathrm{mg}$ or $300 \mathrm{mg}$ twice a day, 690 subjects with Type I diabetes and moderate renal impairment showed a statistically significant reduction in total urinary protein after 36 months compared with the placebo group $(-0.6 \mathrm{gm}$ a day vs $-0.3 \mathrm{gm}$ a day respectively, $p<0.001)$. Paradoxically, the effect was greater in the lower dose group compared with the higher dose group. 


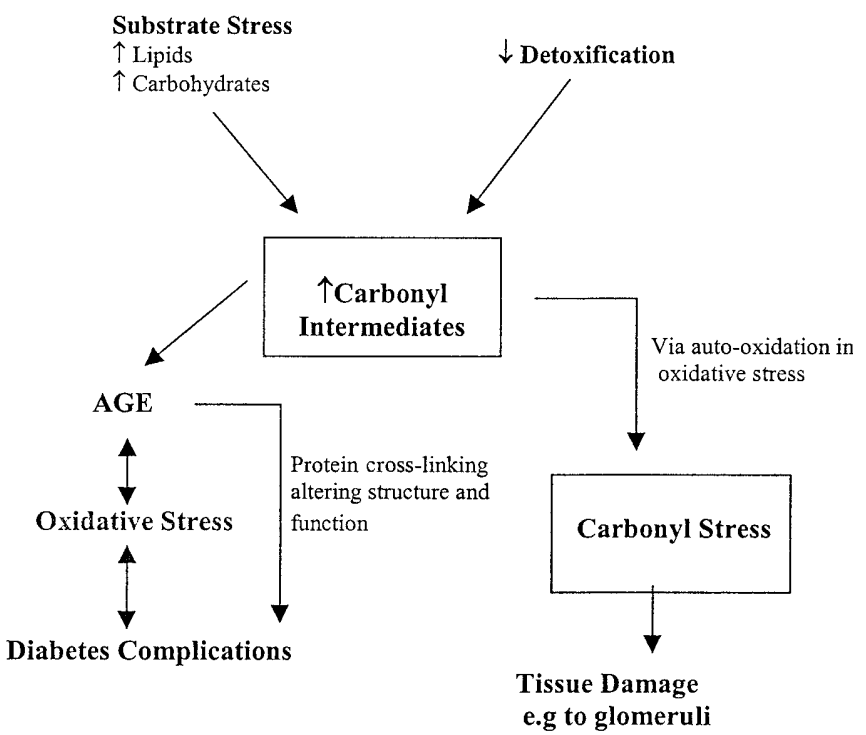

Fig. 4. Carbonyl intermediates and their fate in diabetes or uraemia

Diabetic nephropathy and the concept of carbonyl stress. Carbonyl stress represents the accumulation of reactive di-carbonyls such as $3-\mathrm{DG}$ and $\mathrm{MGO}$, whether because of substrate increase, reduced detoxification, or renal clearance [129]. Such intermediates can go on to form AGE or during accumulation, as in carbonyl stress, they can cause damage themselves (Fig. 4). Evidence for carbonyl stress induced pathology, which is largely in vitro, includes stimulation of osteoclast bone absorption [130,131], proliferation of vascular smooth muscle, stimulation of monocyte chemotaxis and macrophage recruitment [41]. This suggests that they influence tissue repair and remodelling and apoptosis [33].

Reactive carbonyl accumulation leading to carbonyl stress has been proposed as a cause for glomerular damage and the accelerated vascular damage observed in subjects with diabetes mellitus and ESRD (Fig. 4) [42]. This is evident from detection of carbonyls using spectrophotometric assays, showing that uraemic subjects have higher blood concentrations than control subjects, but with values falling after dialysis [41]. In ESRD, concentrations rise, however, whether or not subjects are diabetic, suggesting that hyperglycaemia is not a pre-requisite for accumulation [132].

Continuous ambulatory peritoneal dialysis and haemodialysis can only clear the free rather than the albumin bound forms of pentosidine and CML, suggesting the importance of molecular weight in clearance [133]. In addition after transplantation, AGE concentrations fall as the glomerular filtration rate and creatinine clearance rise. This has prompted the notion that the dramatic improvement in survival following transplantation might depend on a reduction in AGE induced toxicity [83], which some suggest is partly due to carbonyl overload secondary to carbonyl stress [132].

AGE, lipids and diabetic atherosclerotic disease. Diabetes is one of the major independent risk factors for cardiovascular disease [3]. The AGE have effects on lipids, lipid metabolism and the development of atherosclerosis, which could influence diabetes related vascular disease.

Using ELISA and immunohistochemistry AGE have been observed in fatty streaks, atherosclerotic lesions, lipid containing smooth muscle cells and macrophages from diabetic subjects [83, 85, 93, 134]. A correlation between tissue AGE concentrations and the severity of atherosclerotic lesions has also been shown [93]. The AGE accumulation in the extracellular matrix of atheromatous arteries might result in enhanced sub-intimal protein and lipoprotein deposition with covalent trapping of LDL as well as nitric oxide depletion [93, 135].

Animal studies using soluble RAGE, to block the RAGE receptor, resulted in suppression of vascular lesion formation and reduced vascular permeability [68]. These responses occurred independent of lipid and glycaemic changes suggesting that other mechanisms are important for vascular lesion formation.

Susceptibility to atherosclerotic lesion formation by AGE has been shown by in vitro studies indicating endothelial dysfunction manifesting as changes in vascular permeability, coagulation and increased adherence or migration of macrophages and T-lymphocytes into the intima, with the initiation of a prolonged sub-inflammatory response [32, 58, 93]. Endothelial migration of monocytes, considered to be one of the first steps in atherogenesis, is dependent on the up-regulation of vascular cell adhesion moleccule-1 (VCAM-1) expression [136]. Advanced glycation end-products have been shown to increase VCAM-1 expression by activating of NF- $x \mathrm{~B}$ [136]. Recent in vitro work has shown that $\alpha$-lipoic acid, a natural anti-oxidant, can reduce AGE induced endothelial expression of VCAM-1 and hence monocyte binding to the endothelium [136].

Low-density lipoproteins can exist as oxidised LDL, glycated LDL and glycoxidated LDL. Advanced glycation end-products linked to lipids has been shown to initiate oxidative modification with the formation of oxidised LDL and VLDL [19, 135, 137]. In diabetes a greater portion of LDL is glycated and oxidised $[3,19,76,77]$. The LDL receptor does not recognise modified LDL, which is taken up by macrophage scavenger receptors (MSR) or AGE receptors resulting in lipid-laden foam cells in the arterial intima and the promotion of atherosclerosis [138]. Using ELISA methods a positive correlation has been shown between arterial wall AGE and AGE modified LDL in the blood among diabetic subjects [93]. 
Under conditions of hyperglycaemia, glycation of HDL function can reduce paraoxonase activity, which is an HDL-associated ester hydrolase important for the prevention of LDL oxidation. A recent in vitro study [139] has reported a $65 \%$ reduction in paraoxonase activity after glycation of HDL, as well as a decreased ability of both glycated HDL and paraoxonase to prevent monocyte adhesion to aortic endothelial cells. This is an important initial event leading to the development of atherosclerosis. The authors acknowledge that glycation took place under conditions of extreme hyperglycaemia $(25 \mathrm{mmol} / 1$ glucose) and therefore might not reflect physiological conditions. They did, however, show a $40 \%$ reduction in paraoxonase activity in subjects with Type II diabetes and coronary artery disease compared with nondiabetic subjects with coronary heart disease $(p<0.0001)$, albeit in a small number of patients.

Recently it has been shown that $\operatorname{Lp}(\mathrm{a})$ - an independent risk factor for cardiovascular disease undergoes glycation in diabetic subjects [140]. From in vitro studies glycation of $\mathrm{Lp}(\mathrm{a})$ attenuates fibrinolysis by inducing expression of PAI-1 and reducing generation of tissue type-plasminogen activator. Treatment with aminoguanidine normalises these effects.

\section{Treatment targeting AGE}

Exogenous AGE. Although methods to reduce or impair AGE formation centre around drug therapy, other treatment modalities should be considered such as modifiying the intake of food and tobacco derived AGE [51]. The reduction of exogenously derived AGE requires, however, further clarification as we are currently not certain of the significance between these AGE and AGE associated pathology.

Endogenous $A G E$. Therapeutic interventions for reducing AGE formation should target AGE formation by reducing cross-link formation [12]. In addition a reduction in AGE deposition might be achieved using cross-link breakers or by enhancing cellular uptake and degradation. Other strategies could include receptor inhibition of AGE using neutralising antibodies or suppression of post-receptor signalling, using antioxidants. The development of inhibitors, however, might be difficult as AGE are complex and heterogenous. Similarly the complex reactions involved in the advanced glycation process which occur over several stages are not fully understood. In addition in vitro work might not translate to in vivo activity and the AGE selected might not be of physiological importance [141].

To date the most promising agent under investigation is aminoguanidine. Diabetic animal models using aminoguanidine have shown a reduction in diabetes related complications such as retinopathy, neuropa- thy and nephropathy [21, 142]. Specifically, reductions in retinal microvessel formation, albuminuria and the prevention or decrease in motor and sensory nerve conduction velocity have been reported [20]. Recent work using baboons rendered diabetic after the use of streptozotocin, however, did not find that aminoguanidine ameliorated abnormalities in nerve function [118]. Of note, this study examined nerve changes in early diabetes ( $<5$ years duration), suggesting that AGE-induced damage is more relevant at later stages of the disease.

In vitro work has shown that aminoguanidine can act as an antioxidant, quench hydroxyl radicals and cleave cross-links (Table 2) [143]. In addition, aminoguanidine has been reported to lower total cholesterol, LDL cholesterol and triglycerides in diabetic subjects independent of glucose control [19]. It has also been shown to reduce the accumulation of food-derived AGE [144]. Using rats fed a standard diet and AGE-ovalbumin, urine AGE increased from $26 \%$ to $50 \%$ after adding aminoguanidine to the diet. At the same time, tissue bound AGE in the kidney and liver fell from more than $60 \%$ to less than $15 \%$. The mechanism by which aminoguanidine achieves these results is not known but could involve cross-link cleavage leaving more "free" AGE to be excreted by the kidney. Confirmation of this work in humans is required to determine if the increased excretion of AGE has any effect on complications such as diabetic microvascular disease. Carefully controlled dietary intervention studies are also required to determine whether antioxidants are effective in reducing AGE.

A recent phase III trial using pimagedine, has shown beneficial affects on the progression of retinopathy and lipid concentrations [23], in addition to the affects on diabetic nephropathy progression in optimally treated Type I diabetic subjects (Table 3 ) [22]. The reduction in retinopathy progression $(95 \%$ had advanced retinopathy) after 12 months of follow-up was significantly decreased only in the high dose group (300 mg twice a day) compared with the low dose (150 mg twice a day) and placebo groups. Both treatment groups showed, however, statistically significant reductions in total cholesterol and LDL but not HDL after 12 months of treatment. These observations were independent of glycaemic control with $\mathrm{HbA}_{1 \mathrm{c}}$ values being comparable between all groups.

The side effect profile showed a number of unexpected results. A small number of subjects developed flu like symptoms and half became anaemic. This was also noted in placebo patients making it difficult to ascribe this observation entirely to pimagedine therapy and could depend on the anaemia of chronic disease, which could occur in subjects with moderate renal impairment. Early reports on the use of aminoguanidine described, however, blood picture changes resembling pernicious anaemia [145]. Of greater con- 
Table 2. Possible agents for use in AGE treatment

\begin{tabular}{|c|c|c|}
\hline Drug or Agent & Chemical Type & Method of action \\
\hline Aminoguanidine & Hydrazine & $\begin{array}{l}\text { - Traps reactive di-carbonyls impeding conversion to AGE } \\
\text { - Prevents cross-link formation } \\
\text { - Inhibits free radical formation, lipid peroxidation and oxidant induced apoptosis } \\
\text { N.B Large quantities can generate } \mathrm{H}_{2} \mathrm{O}_{2} \text { and so inhibit Catalase. } \\
\text { Depletion of essential carbonyls in the body can also occur e.g. Vitamin B6 }\end{array}$ \\
\hline $\begin{array}{l}\text { Vitamin } \mathrm{C} \text { and } \mathrm{E} \\
\text { Nicarnitine }\end{array}$ & Antioxidants & $\begin{array}{l}\text { - Inhibit oxidative conversion involved in di-carbonyl and AGE formation } \\
\text { - Reduces diabetic retinopathy in rats }\end{array}$ \\
\hline Pyridorin & $\begin{array}{l}\text { An Amadorin also } \\
\text { known as Pyridoxamine }\end{array}$ & - Inhibitor of the conversion of Amadori intermediates to AGE \\
\hline $\mathrm{PTB}^{\mathrm{a}}$ & Thiazolium Compound & $\begin{array}{l}\text { - A cross-link breaker that could cleave di-ketone bridges between } 2 \text { adjacent car- } \\
\text { bonyl groups which could form intermolecular cross-links }\end{array}$ \\
\hline OPB-9195 & $\begin{array}{l}\text { Synthetic Thiazolidine } \\
\text { Derivative }\end{array}$ & $\begin{array}{l}\text { - (Reduced) AGE accumulation in glomeruli and progression of diabetic glomer- } \\
\text { ulosclerosis in rat Type I diabetes models. Thought to work by suppressing TGF- } \\
\beta \text { and VEGF expression }\end{array}$ \\
\hline Losartan & $\begin{array}{l}\text { Angiotensin II receptor } \\
\text { inhibitor }\end{array}$ & $\begin{array}{l}\text { - (Reduction) of serum AGE in rat remnant kidney model. Mechanism unknown, } \\
\text { but was independent of blood pressure changes }\end{array}$ \\
\hline Pyruvate & $\alpha$-keto acid & $\begin{array}{l}\text { - Hypothesised to prevent glycation of protein competitively by forming a Schiff } \\
\text { base between free keto groups and free amino groups in proteins. Also inhibits } \\
\text { oxidative conversion of the initial glycation product to an AGE. }\end{array}$ \\
\hline
\end{tabular}

\footnotetext{
a phenacyl thiazolium bromide

b 2-Isopropyldenehydrazone-4-oxo-thiazolidin-5-ylacetanalide

c 2,3-diamino phenazine
}

Table 3. Summary of Phase III trial results using pimagedine in optimally treated Type I diabetic subjects

\begin{tabular}{|c|c|c|c|}
\hline & Placebo & $\begin{array}{l}\text { Low dose } \\
150 \mathrm{mg} \mathrm{BD}\end{array}$ & $\begin{array}{l}\text { High dose } \\
300 \mathrm{mg} \mathrm{BD}\end{array}$ \\
\hline $\begin{array}{l}\text { Retinopathy progres- } \\
\text { sion }(\%)\end{array}$ & $16 \%$ & $\begin{array}{l}11 \% \\
p 0.112\end{array}$ & $\begin{array}{l}8 \% \\
p 0.044\end{array}$ \\
\hline Lipid reductions & \multicolumn{3}{|c|}{$\begin{array}{l}\text { Mean baseline total cholesterol } \\
5.92 \mathrm{mmol} / 1 \mathrm{LDL} \text { cholesterol } 3.95 \mathrm{mmol} / \mathrm{l}\end{array}$} \\
\hline $\begin{array}{l}\text { Total cholesterol } \\
(\mathrm{mmol} / \mathrm{l})\end{array}$ & 0.14 & $\begin{array}{l}0.56 \\
p<0.001\end{array}$ & $\begin{array}{l}0.48 \\
p=0.008\end{array}$ \\
\hline $\begin{array}{l}\text { LDL cholesterol } \\
(\mathrm{mmol} / \mathrm{l})\end{array}$ & 0.3 & $\begin{array}{l}0.59 \\
p=0.012\end{array}$ & $\begin{array}{l}0.61 \\
p=0.009\end{array}$ \\
\hline $\begin{array}{l}\text { Side effects profile } \\
\text { Flu like illness with } \\
\text { reversible liver } \\
\text { function tests }\end{array}$ & $5 \%$ & $11 \%$ & $13 \%$ \\
\hline Anaemia (\%) & $33 \%$ & $50 \%$ & $40 \%$ \\
\hline Induction of $\mathrm{ANA}^{\mathrm{a}}$ & $29 \%$ & $39 \%$ & $53 \%$ \\
\hline $\begin{array}{l}\text { Induction of } \\
\text { MPO-ANCA }{ }^{\mathrm{b}}(\%)\end{array}$ & $22 \%$ & $31 \%$ & $55 \%$ \\
\hline
\end{tabular}

${ }^{a}$ antinuclear antibody

${ }^{\mathrm{b}}$ myeloperoxidase-antinuclear cytoplasmic antibody

cern was the development of anti-nuclear antibodies and myeloperoxidase-anti-nuclear cytoplasmic antibodies especially in the high dose group, with three subjects developing crescentic glomerulonephritis. One recovered but two developed ESRD [24]. Gen- erally lower dose therapy was well tolerated with a side effect profile comparable to placebo. These results imply that patients using pimagedine require assessment of full blood counts and autoimmune status before and during therapy. Measures of vasculitic activity including erythrocyte sedimentation rate, C-reactive protein, and urinary sediment as well as physical examination also need to be considered. In addition aminoguanidine is known to inhibit diamine oxidase, which catalyses deamination of diamines such as histamine [145]. This has the possibility of raising histamine concentrations with the attendant vascular and respiratory side effects. To date, there are no reports of increased histamine, or induced side effects secondary to aminoguanidine therapy.

Although early studies using diabetic rats treated with aminoguanidine have recorded higher rates of pancreatic and renal neoplasms [25], there are no reports so far, on antibody generation. Aminoguanidine is, however, a hydrazine derivative as is hydralazine [146], which itself is associated with antihistone and antinuclear cytoplasmic antibody production as well as a clinical situation similar to lupus [147]. Although the mechanism for auto-antibody production as a result of hydrazine-hydrazine derivative therapy is not known, there is some evidence that it could involve T-lymphocyte function associated antigen- 1 over expression and autoreactivity [148]. 
Based on the current phase III trial outcomes and considering the side-effect profiles there is no greater benefit in taking the higher dose of pimagedine. It is, however, not known how well the drug would work in patients who are not optimally treated, if treatment should be initiated at the time of diagnosis of diabetes or if a longer follow-up period would have separated outcome measures in the 2 treatment arms. Similarly studies would need to be extended to the population of Type II diabetic subjects. Recent studies using the angiotensin II receptor inhibitor Losartan (Table 2), have shown reduced serum AGE concentrations in normotensive sub-totally nephrectomized rats [149]. This effect was independent of blood pressure and could have been mediated by improvements in renal function after therapy. Further studies are required to determine the effect of AII inhibitor use on AGE excretion in subjects with normal renal function and blood pressure.

In vitro and animal models have shown the effectiveness of other agents to reduce AGE accumulation (Table 2). These agents act by inhibiting oxidant activity such as vitamin C [142] and nicarnitine [150], others by cleaving cross-link formation such as phenacyl thiazolim bromide [141, 151-153] or by directly inhibiting the conversion of Amadori intermediates to AGE, such as pyridorin [138]. Agents such as OPB-9195 [123], 2,3 di-amino phenazine (2, 3 DAP) [154], pyruvate [115] and the monoclonal antibody A717 [155] also have effects on AGE accumulation, but their mechanism of action has not been fully determined (Table 2). Apart from aminoguanidine, all these agents are still at the experimental stage.

In vitro studies using four agents that might inhibit hyperglycaemia, induced damage have recently been reported [36]. Specifically they looked at three pathways which can lead to diabetic complications such as the formation of AGE, the aldose reductase pathway and activation of protein kinase and hence NF$x \mathrm{~B}$ [36]. Using bovine aortic endothelial cells and conducting experiments examining the tricarboxylic acid cycle in mitochondria, they showed that mitochondria could be the source of excess superoxide production as a result of hyperglycaemia. After the use of four inhibitors: thenoyltrifluoroacetone, which inhibits complex II in the mitochondrial electron transport chain; and carbonyl cyanide m-chlorophenylhydrazone, uncoupling protein-1, and manganese superoxide dismutase, which are uncouplers of oxidative phosphorylation, they were able to show a reduction in hyperglycaemic-induced intracellular AGE formation, sorbitol accumulation as well as protein kinase and $\mathrm{NF}-x \mathrm{~B}$ activation. Although this is only a preliminary report, these experiments suggest that mitochondrial superoxide overproduction could play a central part in diabetes related complications and agents directed at reducing superoxide concentrations, or dismutating it could be of benefit.
In conclusion there is increasing evidence of the presence of AGE in a diabetes and its complications. Animal and in vitro studies have shown that AGE affect cellular signalling, activation of transcription factors and subsequent gene expression. A number of receptors for AGE have been identified but their physiological roles need to be determined. The role of AGE and specifically which particular AGE is involved in the aetiology of diabetic micro and macrovascular complications is, however, yet to be established. Despite these concerns recent phase III trial results, using pimagedine, suggest that reducing AGE accumulation could benefit subjects with Type I diabetes. Further trials are required in Type II diabetic subjects and patients with ESRD with or without diabetes. The possibility of effective therapeutic intervention stresses the importance of detecting AGE and advancements in measuring AGE using reliable methods will help determine the role they have in the pathogenesis of many diseases, especially diabetes and its complications.

Acknowledgements. R. Singh is a recipient of a National Health and Medical Research Council (Australia) (NH \& $\mathrm{MRC}$ ) "Centre of excellence in training for cardiovascular research" scholarship.

\section{References}

1. The DCCT Research Group (1993) The effect of intensive diabetes treatment on the development and progression of long term complications in insulin dependent diabetes mellitus: the diabetes control and complications trial New Eng J Med 329: 977-986

2. Anonymous (1998) Intensive blood glucose control with sulphonylureas or insulin compared with conventional treatment and risk of complications in patients with Type II diabetes: (UKPDS 33). Lancet 352: 837-851

3. Omar Farouque HM, O'Brien RC, Meredith IT (2000) Diabetes and coronary heart disease-from prevention to intervention: Part 1. Aust N Z J Med 30: 351-359

4. Anonymous (1998) Tight blood pressure control and risk of macrovascular and microvascular complications in type 2 diabetes: (UKPDS 38). BMJ 317: 703-711

5. John WG, Lamb EJ (1993) The maillard or browning reaction in diabetes. Eye 7: 230-237

6. Chiarelli F, de Martino M, Mezzetti A et al. (1999) Advanced glycation end-products in children and adolescents with diabetes mellitus: relation to glycaemic control and early microvascular complications. J Pediatr 34: 486-491

7. Lee AT, Cerami A (1992) Role of glycation in aging. Ann NY Acad Sci 663: 63-70

8. Bucala R, Cerami A (1992) Advanced glycation: chemistry, biology and implications for diabetes and aging. Adv Pharmacol 23: 1-34

9. Raj DS, Choudhury D, Welbourne TC, Levi M (2000) AGE: a nephrologist's perspective. Am J Kidney Dis 35: 365-380

10. Fishbane S, Bucala R, Pereira BJ et al. (1997) Reduction of plasma apolipoprotein B by effective removal of circulating glycation derivatives in uraemia. Kidney Int 52: 1645-1650 
11. Sugiyama S, Miyata T, Horie K et al. (1996) Advanced glycation end products in diabetic nephropathy. Nephrol Dial Transplant 11[Suppl 5]: 91-94

12. Bierhaus A, Hofmann MA, Ziegler R, Nawroth PP (1998) AGE and their interaction with AGE-receptors in vascular disease and diabetes. I. The AGE concept. Cardiovasc Res 37: 586-600

13. Masaki H, Okano Y, Sakurai H (1999) Generation of oxygen species from AGE during ultrviolet light A (UVA) irradiation and a possible mechanism for cell damage. Biochim Biophys Acta 1428: 45-56

14. Munch G, Thome J et al. (1997) AGE's in aging and alzheimers disease. Brain Res Rev 23: 134-143

15. Takahashi M, Kushida K, Ohishi T et al. (1994) Quantitative analysis of cross-links pyridinoline and pentosidine in articular cartilage of patients with bone and joint disorders. Arthritis Rheum 37: 724-728

16. Sell DR, Monnier VM (1990) End stage renal disease and diabetes catalyse the formation of a pentose-derived cross-link form aging human collagen. J Clin Invest 85: 380-384

17. Nicholl ID, Bucala R (1998) AGE and cigarette smoking. Cell Mol Biol 44: 1025-1033

18. O'Brien J, Morrissey PA (1989) Nutritional and toxocological aspects of the maillard browning reaction in foods. Crit Rev Food Sci Nutr 28: 211-248

19. Bucala R (1997) Lipid and lipoprotein modification by AGE's: role in atherosclerosis. Exp Physiol 82: 327-337

20. Vlassara H (1996) AGE's and atherosclerosis. Ann Med 28: 419-426

21. Ulrich P, Zhang X (1997) Pharmacological reversal of AGE-mediated protein cross-linking. Diabetologia 40: S147-S159

22. Appel G, Bolton K, Freedman B et al. (1999) Pimagedine lowers total urinary protein and slows progression of overt diabetic nephropathy in patients with type I diabetes. J Am Soc Nephrol 10: 153A (Abstract)

23. Raskin P, Caltran D, William M et al. (1999) Pimagedine reduces progression of retinopathy and lowers lipid concentrations in patients with type I diabetes. J Am Soc Nephrol 10: 179A (Abstract)

24. Whittier F, Spinowitz B, Wuerth JP et al. (1999) Pimagedine safety profile in patients with Type I diabetes. J Am Soc Nephrol 10: 184A (Abstract)

25. Boel E, Selmer J, Flodgaard HJ, Jensen T (1995) Diabetic late complications: will aldose reductase inhibitors or inhibitors of advanced glysosylation end-product formation hold promise? J Diabetes Complications 9: 104-129

26. Vlassara H, Bucala R (1996) Recent progress in advanced glycation and diabetic vascular disease: role of AGE receptors. Diabetes 45 [Suppl 3]: S65-S66

27. Furth A (1997) Glycated proteins in diabetes. Br J Biomed Sci 54: 192-200

28. McCance DR, Dyer DG, Dunn JA et al. (1993) Maillard reaction products and their relation to complications in insulin dependent diabetes mellitus. J Clin Invest 91: 2470-2478

29. Chappey O, Dosquet C, Wautier M-P, Wautier J-L (1997) Advanced glycation end products, oxidant stress and vascular lesions. Eur J Clin Invest 27: 97-108

30. Miyata T, Maeda K, Kurokawa K, van Ypersele de Strihou C (1997) Oxidation conspires with glycation to generate noxious advanced glycation end-products in renal failure. Nephrol Dial Transplant 12: 255-258

31. Skovsted IC, Christensen M, Breinholt J (1998) Characterisation of a novel age-compound derived from lysine and 3-deoxyglucasone. Cell Mol Biol 44: 1159-1163
32. Wells-Knecht KJ, Brinkmann E, Wells-Knecht MC et al. (1996) New biomarkers of maillard reaction damage to proteins. Nephrol Dial Transplant 11 [Suppl 5]: 41-47

33. Baynes JW, Thorpe SR (1999) Role of oxidative stress in diabetic complications a new perspective on an old paradigm. Diabetes 48: 1-9

34. Mlakar A, Spiteller G (1994) Re-investigation of lipid peroxidation of linoleic acid. Biochim Biophys Acta 1214: 209-220

35. Sima AA, Sugimoto K (1999) Experimental diabetic neuropathy: an update. Diabetologia 42: 773-788

36. Nishikawa T, Edelstein D, Du XL et al. (2000) Normalising mitochondrial superoxide production blocks three pathways of hyperglycaemia induced damage. Nature 404: 787-789

37. Thornalley PJ (1996) Pharmacology of methylglyoxal. Gen Pharmacol 27: 565-573

38. Thornalley PJ, Westwood M, Lo TW, McLellan AC (1995) Formation of methylglyoxal - modified proteins in vitro and in vivo and their involvement in AGE - related processes. Contrib Nephrol 112: 24-31

39. Thornalley PJ, Langborg A, Minhas HS (1999) Formation of glyoxal, methylglyoxal and 3-DG in the glycation of proteins. Biochem J 344: 109-116

40. Okado A, Kawasaki Y, Husuike Y et al. (1996) Induction of apoptic cell death by methylglyoxal and 3-deoxyglucasone in macrophage derived cell lines. Biochem Biophys Res Commun 225: 219-224

41. Miyata T, van Ypersele de Strihou C, Kurakawa K, Baynes JW (1999) Alteration in non-enzymatic biochemistry in uraemia: origin and significance of "carbonyl stress" in long term uraemic complications. Kidney Int 55: 389-399

42. Suzuki D, Miyata T, Saotome N et al. (1999) Immunohistochemical evidence for an increased oxidative stress and carbonyl modification in protein in diabetic glomerular lesions. J Am Soc Nephrol 10: 822-832

43. Frye EB, Degenhardt TP, Thorpe SR et al. (1998) Role of the maillard reaction in aging of tissue proteins. $\mathrm{J}$ Biol Chem 273: 18714-18719

44. Miyata T, Ueda Y, Shinzato T et al. (1996) Accumulation of albumin - linked and free-from pentosidine in the circulation of uraemic patients with end-stage renal failure: renal implications in the pathology of pentosidine. J Am Soc Nephrol 7: 1198-1206

45. Fu M-X, Wells-knecht KJ, Blackledge JA et al. (1994) Glycation, glyoxidation and cross-linking of collagen by glucose: kinetics, mechanisms and inhibition of late stages of the maillard reaction. Diabetes: 676-683

46. Ando K, Beppu M, Kikugawa K, Nigai R, Horiuchi S (1999) Membrane proteins of human erythrocytes are modified by advanced glycation end-products during aging in the circulation. Biochem Biophys Res Commun 258: $123-127$

47. Fu M-X, Requena JR, Jenkins AJ et al. (1996) The advanced glycated end-product N-(carboxymethyl) lysine, is a product of both lipid peroxidation and glyoxidation reactions. J Biol Chem 271: 9982-9986

48. Requena JR, Fu M-X, Ahmed MU et al. (1996) Lipoxidation products as biomarkers of oxidative damage to protein during lipid peroxidation reactions. Nephrol Dial Transplant 11 [Suppl 5]: 48-53

49. Kennedy L (1992) Glycation of immunoglobulins and serum proteins. In: Alberti KGMM, de Fronzo RA, Keen H, Zimmet P (eds) International Textbook of Diabetes Mellitus, 2nd edn. John Wiley, Chichester pp 985-1007 
50. Cerami C, Founds H, Nicholl I et al. (1997) Tobacco smoke is a source of toxic reactive glycation products. Proc Natl Acad Sci USA 94: 13915-13920

51. Koschinsky T, He CJ, Mitsuhashi Tet al. (1997) Orally absorbed reactive glycation products (glycotoxins): an environmental risk factor in diabetic nephropathy. Proc Natl Acad Sci USA 94: 6474-6479

52. Ross R (1993) The pathogenesis of atherosclerosis: a perspective for the $1990 \mathrm{~s}$. Nature 362: 801-809

53. Monnier VM, Glomb M, Elgawish A, Sell DR (1996) The mechanism of collagen cross-linking in diabetes: a puzzle nearing resolution. Diabetes 45 [Suppl 3]: 367-372

54. Dyer GK, Dunn JA, Thorpe SR et al. (1993) J Clin Invest 91: 2463-2469

55. Paul RG, Bailey AJ (1999) The effect of advanced glycated end-product formation upon cell-matrix interaction. Int J Biochem Cell Biol 31: 653-660

56. Sims TJ, Rasmussen LM, Oxlund H, Bailey AJ (1996) The role of glycation cross-links in diabetic vascular stiffening. Diabetologia 39: 946-951

57. Miyata S, Monnier VM (1992) Advanced glycated endproducts in diabetic tissues using monoclonal antibody to pyrraline J Clin Invest 89: 1102-1112

58. Stitt AW, Bucala R, Vlassara H (1997) Atherogenesis and advanced glycation: promotion, progression and prevention. Ann NY Acad Sci 811: 115-129

59. Thornalley PJ (1998) Cell activation by glycated proteins, AGE receptors, receptor recognition factors and functional classification of AGE. Cell Mol Biol 44: 1013-1023

60. Pugliese G, Pricci F, Leto G et al. (2000) Diabetes 49: 1249-1257

61. Bierhaus A, Ziegler R, Nawroth PP (1998) Molecular mechanisms of diabetic angiopathy clues for innovative theraputic interventions. Horm Res 50 [Suppl 1]: 1-5

62. Lander HM, Tauras JM, Ogiste JS, Hori O, Moss RA, Schmidt AM (1997) Activation for the receptor for AGE triggers a p21 ras dependent mitogen activated protein kinase pathway regulated by oxidant stress. J Biol Chem 272: $17810-17814$

63. Schmidt AM, Hori O, Cao R et al. (1996) RAGE a novel receptor for AGE's. Diabetes 45 [Suppl 3]: S77-S80

64. Yan SD, Schmidt AM, Anderson GM et al. (1994) Enhanced cellular oxidant stress by the interaction of AGE's with their receptors/binding proteins J Biol Chem 269: 9889-9897

65. Schmidt AM, Hori O, Brett J, Yan SD, Wautier J, Stern D (1994) Cellular receptors for AGE's: implication for induction of oxidant stress and cellular dysfunction in the pathogenesis of vascular lesions. Arterioscler Thromb 14: $1521-1528$

66. Bierhaus A, Chevion S, Chevion M et al. (1997) Advanced glycation end-products induced activation of NF$\varkappa \mathrm{B}$ is suppressed by $\alpha$-lipoic acid in cultured endothelial cells. Diabetes 46: 1481-1490

67. Neumann A, Schinzel R, Palm D, Riederer P, Munch G (1999) High molecular weight hyaluronic acid inhibits advanced glycation end-product induced NF-kappaB activation and cytokine expression. FEBS Letters 453: 283-287

68. Anderson MM, Requena JR, Crowley JR, Thorpe SR, Heinecke JW (1999) The myeloperoxidase system of human phagocytes generates N-epsilon-(carboxymethyl)lysine in proteins: a mechanism for producing advanced glycation end-products at sites of inflammation. J Clin Invest 104: 103-113

69. Schmidt AM, Yan SD, Wautier J-L, Stern D (1999) Activation of receptor for advanced glycation end-products: a mechanism for chronic vascular dysfunction in diabetic vasculopathy and atherosclerosis. Circ Res 84: 489-497

70. Huttenen HJ, Fages C, Rauvala H (1999) Receptor for advanced glycated end-products (RAGE)-mediated neurite outgrowth and activation of NF-kappa B require the cytoplasmic domain of the receptor but different downstream signalling pathways. J Biol Chem 274: 19919-19924

71. Fages C, Nolo R, Huttunen HJ, Eskelinen EL, Ravvala H (2000) Regulation of cell migration by amphoterin. J Cell Sci 113: 611-620

72. Taguchi A, Blodd DC, del Toro G et al. (2000) Blockade of RAGE-amphoterin signalling suppresses tumour growth and metastases. Nature 405: 354-360

73. Baumgartner-Parzer SM (1997) Glycaemia and the regulation of endothelial adhesion molecules. Horm Metab Res 29: 636-638

74. King GL, Shiba T, Oliver J, Inoguchi T, Bursell SE (1994) Cellular molecular abnormalities in the vascular endothelium of diabetes mellitus. Ann Rev Med 45: 179-181

75. Kennedy L, Baynes JW (1984) Non-enzymatic glycosylation and the chronic complications of diabetes: an overview. Diabetologia 26: 93-98

76. Brownlee M (1995) Advanced glycosylation in diabetes and aging. Ann Rev Med 46: 223-234

77. Makita Z, Yunagisawa K, Kawajima S, Bucala R, Vlassara H, Koike T (1996) The role of advanced glycation end products in the pathogenesis of atherosclerosis. Nephrol Dial Transplant 11 [Suppl 5]: 31-33

78. Sano H, Higashi T, Matsumoto K et al. (1998) Insulin enhances macrophage scavenger receptor mediated endocytic uptake of advanced glycated end products. J Biol Chem 273: 8630-8637

79. Makita Z, Radoff S, Rayfield EJ et al. (1991) Advanced glycation end products in diabetic nephropathy. New Eng J Med 325: 836-842

80. Smedsrod B, Melkko J, Araki N, Sano H, Horiuchi S (1997) AGE's are eliminated by scavenger receptor mediated endocytosis of hepatic sinusoidal kupffer cells and endothelial cells. Biochem J 322: 567-573

81. Hsueh WA, Law RE (1998) Cardiovascular risk continuum: implication of insulin resistance and diabetes. Am J Med 105: 4S-14S

82. Nakayama H, Tanade S, Mitsuhashi T et al. (1991) Characterisation of antibody to advanced glycated end-products on protein. J Immunol Methods 140: 119-125

83. Friedman EA (1999) Advanced glycosylated end-products and hyperglycaemia in the pathogenesis of diabetic complications. Diabetes Care 22 [Suppl 2]: B65-B71

84. Berg TJ, Dahl-Jorgensen K, Torjensen PA, Hanssen KF (1997) Increased serum concentrations of advanced glycated end-products (AGE) in children and adolescents with IDDM. Diabetes Care 20: 1006-1008

85. Schleicher ED, Wagner E, Nerlich AG (1997) Increased accumulation of the glyoxidation product $\mathrm{N}$ (epsilon)(carboxymethyl)lysine in human tissues in diabetes and aging. J Clin Invest 99: 457-468

86. Yoshihara K, Nakamura K, Kanai M et al. (1998) Determination of urinary and serum pentosidine and its application to older patients. Biol Pharm Bull 21: 1005-1008

87. Takahashi M, Suzuki M, Kushida K, Miyamoto S, Inoue T (1997) Relation between pentosidine concentrations in serum and urine and activity of rheumatoid arthritis. Brit J Rheumatol 36: 637-642

88. Papanastasiou P, Grass L, Rodela H, Patrikarea A, Oneopoulos D, Diamandis EP (1994) Immunological quantification of AGE's in serum of patients on haemodialysis or peritoneal dialysis. Kidney Int 46: 216-222 
89. Takahashi M, Kushida K, Kawana K et al. (1993) Quantification of the cross-link pentosidine in serum from normal and uremic subjects. Clin Chem 39: 2162-2165

90. Radoff S, Makita Z, Vlassara H (1991) Radioreceptor assay for advanced glycation end-products. Diabetes 40: 1731-1738

91. Portero-Otin M, Nagaraj RH, Monnier VM (1995) Chromatographic evidence for pyrraline formation during protein glycation in vitro and in vivo. Biochim Biophys Acta 1247: 74-86

92. Knecht KJ, Feather MS, Baynes JW (1992) Detection of 3-deoxyfructose and 3-deoxyglucosone in human urine and plasma. Arch Biochem Biophys 294: 130-137

93. Stitt AW, He C, Friedman S et al. (1997) Elevated AGEmodified Apo B in sera of euglycaemic, normolipidaemic patients with atherosclerosis: relation to tissue AGE. Mol Med 3: 617-627

94. Mitsuhashi T, Vlassara H, Founds HW, Li YM (1997) Standardising the immunological measurement of advanced glycation end products using normal human serum. J Immunol Methods 207: 79-88

95. Munch G, Keis R, Wessels A et al. (1997) Determination of advanced glycation end products in serum by fluorescence spectroscopy and competative ELISA. . Eur J Clin Chem Clin Biochem 35: 669-677

96. Soulis T, Thallas V, Youssef S et al. (1997) Advanced glycation end-products and their receptors co-localise in rat organs susceptible to diabetic microvascular injury. Diabetologia 40: 619-628

97. Yoshida S, Yamada K, Hamaguchi K et al. (1998) Immunohistochemical study of human advanced glycation endproducts (AGE) and growth factors in cardiac tissue of patients on maintenance dialysis and kidney transplantation. Clin Nephrol 49: 273-280

98. Ikeda K, Higashi T, Sano H et al. (1996) N (epsilon)(carboxymethyl)lysine protein adduct is a major immunological epitope in proteins modified with advanced glycation end products of the maillard reaction. Biochemistry 35: 8075-8083

99. Ishii H, Jirousek MR, Koya D et al. (1996) Amelioration of vascular dysfunction in diabetic rats by an oral protein kinase $\mathrm{C}$ beta inhibitor. Science 272: 728-731

100. Sima AA, Prashar A, Zhang WX, Chakrabarti S, Greene DA (1990) Preventative effect of long term aldose reductase inhibitor (ponalrestat) on nerve conduction and sural nerve structure in the spontaneously diabetic Bio-Breeding rat. J Clin Invest 85: 1410-1420

101. Park KL, Ramaw KG, Lee KJ et al. (1998) Suppression of accelerated diabetic atherosclerosis by the soluble receptor for advanced glycated end-products. Nat Med 4: 1025-1031

102. Ceriello A (1999) Hyperglycaemia: the bridge between non-enzymatic glycation and oxidative stress in the pathogenesis of diabetic complications. Diabetes Nutr Metab 12: $42-46$

103. Scivittaro V, Ganz MB, Weiss MF (2000) AGE induce oxidative stress and activate protein kinase C-beta (II) in neonatal mesangial cells. Am J Physiol 278: F676-F683

104. Dahl-Jorgensen K (1998) Biochemical markers of diabetic microangiopathy. Past, present and future. Horm Res 50 [Suppl 1]: 12-16

105. Strano A, Davi G, Patrono C (1991) In vivo platelet activation in diabetes mellitus. Semin Thromb Hemost 17: 422-425

106. Ritthaler U, Deng Y, Zhang Y et al. (1995) Expression of receptors for AGE's in peripheral occlusive vascular disease. Am J Pathol 146: 688-694
107. Ceriello A, Marchi E, Barbanti M et al. (1990) Non-enzymatic glycation reduces heparin cofactor II anti-thrombin activity. Diabetologia 33: 205-207

108. Vlassara H, Bucala R, Striker L (1994) Pathogenic effects of advanced glycosylation: biochemical, biological and chemical implications for diabetes and aging. Lab Invest 70: $138-151$

109. Stitt AW, Li YM, Gardiner TA, Bucala R, Archer DB, Vlassara H (1997) Advanced glycated end-products (AGE) co-localise with AGE receptors in the retinal vasculature of diabetic and AGE infused rats. Am J Pathol 150: 523-539

110. Yamagishi S-C, Yonekura H, Yamamoto Y et al. (1997) Advanced glycated end-product driven angiogenesis in vitro J Biol Chem 272: 8723-8730

111. Murata T, Nagai R, Ishibashi T, Inomoto H, Ikeda K, Horiuchi S (1997) The relation between accumulation of advanced glycated end-products and expression of vascular endothelial growth factor in human diabetic retinas. Diabetologia 40: 764-769

112. Hammes HP, Alt A, Niwa T et al. (1999) Differential accumulation of advanced glycated end-products in the course of diabetic retinopathy. Diabetologia 42: 728-736

113. Brownlee M (2000) Negative consequences of glycation. Metabolism 49 [2 Suppl 1]: 9-13

114. Stevens A (1998) The contribution of glycation to cataract formation in diabetes. J Am Optom Assoc 69: 519-530

115. Zhao W, Devamanoharan PS, Varma SD (2000) Fructose mediated damage to lens alpha-crystallin: prevention by pyruvate. Biochim Biophys Acta 1500: 161-168

116. Loske C, Neumann A, Cunningham AM et al. (1998) Cytotoxicity of advanced glycation end-products is mediated by oxidative stress. J Neural Transm 105: 1005-1015

117. Vlassara H, Brownlee M, Cerami A (1981) Non-enzymatic glycosylation of peripheral nerve protein in diabetes. Proc Natl Acad Sci USA 78: 5190-5192

118. Birrell AM, Heffernan SJ, Ansselin AD, Mclennan S, Church DK, Gillari AG (2000) Functional and structural abnormalities in the nerves of Type I diabetic baboons: aminoguanidine does not improve nerve function. Diabetologia 43: 110-116

119. Federoff JH, Lawrence D, Brownlee M (1993) Non-enzymatic glycosylation of laminin and the laminin peptide CI-KVAVS inhibits neurite outgrowth. Diabetes 42: 509-513

120. Giardino I, Edelstein D, Brownlee M (1994) Non-enzymatic glycosylation in vitro and in bovine endothelial cells alters basic fibroblast growth factor activity: a model for intracellular glycosylation in diabetes. J Clin Invest 94: 110-117

121. Sugimoto K, Nishizawa Y, Horiuchi S, Yagihashi S (1997) Localisation in human diabetic peripheral nerve of $\mathrm{N}$ epsilon-carboxymethyl-lysine protein adducts, an advanced glycated end-product. Diabetologia 40: 1380-1387

122. Shinpo K, Kikuchi S, Sasaki H et al. (2000) Selective vulnerability of spinal motor neurones to reactive dicarbonyl compounds, intermediate products of glycation, in vitro: implication of inefficient glutathione system in spinal motor neurones. Brain Res 861: 151-159

123. Tuschida K, Makita Z, Yamagishi S et al. (1999) Suppression of transforming growth factor beta and vascular endothelial growth factor in diabetic nephropathy in rats by a novel advanced glycation end-product inhibitor OPB9195. Diabetologia 42: 577-588

124. Lee HB, Cha MK, Song KI et al. (1997) Pathogenic role of AGE's in diabetic nephropathy. Kidney Int 52 [Suppl 66]: S60-S65 
125. Sharma K, Ziyadeh FN (1995) Hyperglycaemia and diabetic kidney disease. The case for transforming growth factor beta as a key mediator. Diabetes 44: 1139-1146

126. Iijima K, Yoshikawa N, Connolly DT, Nakamura H (1993) Human mesangial cells and periheral blood mononuclear cells produce vascular permeability factor. Kidney Int 44: 959-966

127. Brownlee M, Cerami A, Vlassara H (1988) Advanced glycated end-products in tissue and the biochemical basis of diabetic complications. New Eng J Med 318: 1315-1321

128. Bendayan M (1998) Immunocytochemical detection of AGE's in rat renal tissue as a function of age and diabetes. Kidney Int 54: 438-447

129. Wada T, Miyata T, Kurokawa K (1999) Implication of carbonyl stress in long term uraemic complications. Nephrol Dial, Transplant 14 [Suppl 1]: 79-81

130. Miyata T, Sprague SM (1996) Advanced glycation of $\beta 2$ microglobulin in the pathogenesis of bone lesions in dialysis associated amyloidosis. Nephrol Dial Transplant 11 [Suppl 3]: 86-90

131. Miyata T, Notoya K, Yoshida K et al. (1997) Advanced glycation end-products enhance osteoclast-induced bone resorption in cultured mouse infractionated bone cells and in rats implanted subcutaneously with devitalised bone particles. J Am Soc Nephrol 8: 260-270

132. Miyata T, Ueda Y, Saito A, Kurokawa K (2000) "Carbonyl stress" and dialysis related amyloidosis. Nephrol Dial Transplant 15 [Suppl 1]: 25-28

133. Miyata T, Ueda Y, Yoshida A et al. (1997) Clearance of pentosidine, an advanced glycated end-product, by different modalities of renal replacement therapy. Kidney Int 51: $880-887$

134. Nakamura Y, Horii Y, Nishino T et al. (1993) Immunocytochemical localisation of AGE's in coronary atheroma and cardiac tissue in diabetes. Am J Pathol 143: 1649-1656

135. Hoff HF, Whitaker TE, O'Neil J (1992) Oxidation of LDL leads to particle aggregation and altered macrophage recognition. J Biol Chem 267: 602-609

136. Kunt T, Forst T, Wilhelm A et al. (1999) Alpha-lipoic acid reduces expression of vascular cell adhesion molecule-1 and endothelial adhesion of human monocytes after stimulation with advanced glyctaed end-products. Clin Sci (Colch) 96: 75-82

137. Mamo JC, Szeto L, Steiner G (1990) Glycation of VLDL from rat plasma impairs its catabolism. Diabetologia 33: 339-345

138. Sobal G, Sinzinger H, Menzel EJ (1999) Binding of long term glycated low density lipoprotein and AGE-albumin by peripheral monocytes and endothelial cells. J Recept Signal Transduct Res 19: 267-281

139. Hedrick CC, Thorpe SR, Fu M-X et al. (2000) Glycation impairs high density lipoprotein function. Diabetologia 43: $312-320$

140. Zhang JY, Ren S, Shen GX (2000) Glycation amplifies lipoprotein (a)- induced alteration in the generation of fibrinolytic regulators from human vascular endothelial cells. Atherosclerosis 150: 299-308
141. Khalifah RG, Baynes JW, Hudson BG (1999) Amadorins: novel post-amadori inhibitors of advanced glycation endproducts. Biochem and Biophysical Res Commun 257: 251-258

142. Thorpe SR, Baynes JW (1996) Role of the maillard reaction in diabetes mellitus and diseases of aging. Drugs Aging 9: 69-77

143. Giardino I, Fard AK, Hatchell DL, Brownlee M (1998) Aminoguanidine inhibits reactive oxygen species formation, lipid peroxidation and oxidant induced apoptosis. Diabetes 47: 1114-1120

144. He C, Sabol J, Mitsuhashi T, Vlassara H (1999) Dietary glycotoxins: inhibition of reactive products by aminoguanidine facilitates renal clearance and reduces tissue sequestration. Diabetes 48: 1308-1315

145. Nilsson BO (1999) Biological effects of aminoguanidine: an update. Inflammation Research 48: 509-515

146. Goodwin DC, Aust SD, Grover TA (1996) Free radicals produced during the oxidation of hydrazines by hypochlorous acid. Chem Res Toxicol 9: 1333-1339

147. Kallenberg CG, Mulder AH, Tervaert JW (1992) Antineutrophil cytoplasmic antibodies: a still growing class of auto-antibodies in inflammatory disorders. Am J Med 93: 675-682

148. Yung R, Chung S, Hemati N, Johnson K, Richardson B (1997) Mechanism of drug induced lupus. Arthritis Rheum 40: 1436-1443

149. Sebekova K, Schinzel R, Munch G, Krivosikova Z, Dzurik R, Heidland A (1999) Advanced glycation end-product concentrations in sub-totally nephrectomised rats: beneficial effects of angiotensin II receptor I antagonist losartan. Mineral and Electrolyte Metab 25: 380-383

150. Hammes HD, Bortmann A, Engel L, Wulfroth P (1997) Antioxodant treatment of experimental diabetic retinopathy in rats with nicarnitine. Diabetologia 40: 629-634

151. Vasan S, Zhang X, Zhang X et al. (1996) An agent cleaving glucose-derived protein cross-linking in vitro and in vivo. Nature 382: 275-278

152. Booth AA, Khalifah RG, Hudson BG (1996) Thiamine pyrophosphate and pyridoxamine inhibit the formation of antigenic advanced glycation end-products: comparison with aminoguanidine. Biochem Biophys Res Commun 220: 113-119

153. Cooper ME, Thallas V, Forbes J et al. (2000) The crosslink breaker, N-phenacylthiazolium bromide prevents vascular advanced glycated end-product accumulation. Diabetologia 43: 660-664

154. Soulis T, Sastra S, Thallas V et al. (1999) A novel inhibitor of advanced glycation end-product formation inhibits mesenteric vascular hypertrophy in experimental diabetes. Diabetologia 42: 472-479

155. Cohen MP, Ziyadeh FN (1996) Role of amadori modified non-enzymatically glycated serum proteins in the pathogenesis of diabetic nephropathy. J Am Soc Nephrol 7: 183-190 